\title{
Johann Christoph Gottsched und die "philosophische» Predigt
}

Studien zur aufklärerischen Transformation der protestantischen Homiletik im Spannungsfeld von Theologie, Philosophie, Rhetorik und Politik

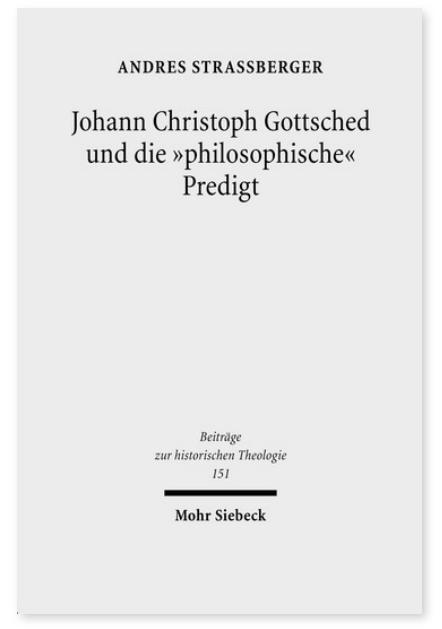

2010. XVI, 646 Seiten. BHTh 151

ISBN 978-3-16-151061-8

DOI 10.1628/978-3-16-151061-8

eBook PDF $179,00 €$

ISBN 978-3-16-150014-5

Leinen $179,00 €$
Andres Straßberger untersucht erstmals die biographischen, geistes- und kulturgeschichtlichen sowie politischen Zusammenhänge und Hintergründe der Predigttheorie (Homiletik) des Leipziger Philosophieprofessors und Literaturreformers Johann Christoph Gottsched (1700-1766). Im Mittelpunkt steht ein von ihm 1740 anonym publiziertes Predigtlehrbuch, das den Anspruch erheben darf, die erste aufklärerische Homiletik in Deutschland zu sein. Andres Straßberger interessiert sich für Trägerschichten, Netzwerke und Strategien der Propagierung von Gottscheds "philosophischer «, d.h. an der Aufklärungsphilosophie Christian Wolffs (1679-1754) ausgerichteten Predigttheorie. Komplementär dazu kommt die Diskussion in aufklärungskritischen Kreisen der Theologie und Öffentlichkeit in den Blick. Es wird versucht, den Prozess der (theologischen) Aufklärung in der ersten Hälfte des 18. Jahrhunderts an einem konkreten Fallbeispiel transparent zu machen.

Der Autor erhielt für seine Dissertation den Hanns-Lilje-Preis 2008 der Akademie der Wissenschaften zu Göttingen und den Nachwuchsförderpreis des Fördervereins der Sächsischen Akademie der Wissenschaften zu Leipzig 2008.

Andres Straßberger Geboren 1968; Studium der Ev. Theologie in Leipzig und Prag; 1999-2004 Wiss. Mitarbeiter am Institut für Kirchengeschichte an der Universität Leipzig; seit 2005 Geschäftsführer des Landeskirchlichen Prüfungsamtes der Ev.Luth. Landeskirche Sachsens; 2007 Promotion.
Jetzt bestellen:

https://mohrsiebeck.com/buch/johann-christoph-gottsched-und-die-philosophische-predigt-9783161510618?no_cache=1 order@mohrsiebeck.com

Telefon: $+49(0) 7071-923-17$

Telefax: $+49(0) 7071-51104$ 